Check for updates

Cite this: RSC Adv., 2019, 9, 1327

\title{
Gold nanoparticle coatings as efficient adenovirus carriers to non-infectable stem cells $\uparrow$
}

\author{
Yulan Hernandez, $\ddagger^{\mathrm{a}}$ Rebeca González-Pastor, (D) $\S^{\text {bc }}$ Carolina Belmar-Lopez, \\ Gracia Mendoza, (iD) ac Jesus M. de la Fuente ${ }^{\text {de }}$ and Pilar Martin-Duque (iD)*bcf
}

\begin{abstract}
Mesenchymal stem cells (MSCs) are adult pluripotent cells with the plasticity to be converted into different cell types. Their self-renewal capacity, relative ease of isolation, expansion and inherent migration to tumors, make them perfect candidates for cell therapy against cancer. However, MSCs are notoriously refractory to adenoviral infection, mainly because CAR (Coxsackie-Adenovirus Receptor) expression is absent or downregulated. Over the last years, nanoparticles have attracted a great deal of attention as potential vehicle candidates for gene delivery, but with limited effects on their own. Our data showed that the use of positively charged $14 \mathrm{~nm}$ gold nanoparticles either functionalized with arginine-glycineaspartate (RGD) motif or not, increases the efficiency of adenovirus infection in comparison to commercial reagents without altering cell viability or cell phenotype. This system represents a simple, efficient and safe method for the transduction of MSCs, being attractive for cancer gene and cell therapies.
\end{abstract}

Received 2nd November 2018 Accepted 24th December 2018

DOI: $10.1039 / \mathrm{c} 8 \mathrm{ra09088b}$

rsc.li/rsc-advances many different cell types and organs, they are good candidates as gene transfer vectors. In particular, adenovirus (Ad) is widely used for in vitro/in vivo gene transfer because of its high transduction efficiency. ${ }^{7,8}$ However, the use of such viruses as gene delivery carriers has been limited by the fact that virus vectors generally cannot enter into many tumoral cells that lack the expression of Ad-associated receptors. The transduction efficiency of Ad is highly dependent upon the expression level of the $46 \mathrm{kDa}$ membrane protein known as CoxsackievirusAdenovirus Receptor (CAR) on the target cell surface. ${ }^{\mathbf{9}, 10}$ The predominant adenoviral serotype currently used in gene therapy applications is human Ad5. ${ }^{11}$ Ad5 entry into cells involves a two-step process that starts with the docking of the knob domain on the distal part of the fiber to CAR, followed by the exposure of an arginine-glycine-aspartate (RGD) motif in the penton base that binds to integrins $\alpha \mathrm{v} \beta 3$ and $\alpha \mathrm{v} \beta 5$ expressed on the cell surface, which promotes Ad endocytosis. ${ }^{12}$ Other receptors, such as heparan sulfate glycosaminoglycans (HS GAGs), are involved in the initial binding and internalization of Ad5. ${ }^{13}$

Since the identification of mesenchymal stem cells (MSCs), an entire branch of research has been dedicated to the analysis of the biology of the MSCs for the development of therapeutic applications. MSCs display a high degree of pluripotency ${ }^{\mathbf{1 4 , 1 5}}$ and the ability to migrate towards and engraft into the tumor sites, ${ }^{\mathbf{1 6 - 1 8}}$ which makes them a great hope for efficient targeted delivery vehicles in cancer gene therapy. ${ }^{19-21}$ Besides, MSCs represent a potent target for gene delivery for both regenerative medicine and clinical therapies (ischemic heart diseases, pancreatic regeneration, neurological disorders, hepatic cirrhosis, limb ischemia, skin regeneration, rheumatoid 
arthritis). ${ }^{22,23}$ Additional modifications of stem cells might be done by using recombinant adenoviral vectors, as they are ideal tools for episomal gene transfer that allows for the manipulation of signaling pathways, reporter gene expression or differentiation of cell lineages. ${ }^{24}$ However, several studies have reported low CAR expression in MSCs which results in lower adenovirus internalization and gene expression efficiency, being essential exploring CAR-independent targeting strategies. $^{25}$

Due to the modular nature of the adenovirus, molecules can be incorporated onto the viral surface to add reactivity to specific sites of the capsid, for therapy or diagnostic (such as the addition of magnetic resonance imaging contrast agents, sensitizers and peptides). ${ }^{26}$ Two methods that have been developed to overcome the CAR deficiency are based on the modification of the adenoviral tropism, one by incorporation of the RGD peptide in the HI loop of the fiber knob and the other by the use of Ad5 vectors possessing fiber proteins from a different serotype. ${ }^{27}$ Both methods might result in an enhancement of mesenchymal cells gene transduction, but genetic manipulation of adenovirus can be very time consuming and, moreover, the resulting significant structural changes can lead to the production of non-viable viruses.

Moreover, adenoviruses can serve as biocompatible scaffolds to which a wide variety of inorganic and biological structures can be attached, and so coating of adenovirus with different systems has already shown great improvements in gene transfer studies. ${ }^{28-30}$ In this context, gold nanoparticles (AuNPs) have attracted considerable attention in basic research because of their various applications, including biomedical applications, ${ }^{31-33}$ used in highly sensitive diagnostic, ${ }^{34,35}$ assays thermal ablation, ${ }^{36}$ radiotherapy enhancement, ${ }^{37,38}$ antibiotic therapy as well as for drug and gene delivery. ${ }^{39,40}$ Another reason for the great expansion of this type of nanomaterials is their relatively easy functionalization with a wide variety of molecules. ${ }^{\mathbf{4 0 - 4 3}}$

In this work, both commercial transfection reagents based on PEI and AuNPs modified with PEG and functionalized to bear positive charge and/or the RGD peptide to enhance the ionic interactions with HS GAGs on the cell membrane and the attachment to the $\alpha v \beta 3$ and $\alpha v \beta 5$ integrins were studied as potential coatings for Ad vectors for gene therapy purposes. Thus, by taking advantage of the properties and flexibility that AuNPs provide, we designed a very promising Ad-based system for highly efficient and safe transduction of MSCs, even compared with commercial transfection agents, which, moreover, broadness the possibilities of Ad vectors on cellular therapy.

\section{Experimental}

\section{Synthesis and functionalization of gold nanoparticles}

AuNPs used had an average diameter of $14 \pm 1 \mathrm{~nm}$ and were synthesized by reduction with sodium citrate as described by Turkevich ${ }^{44}$ and Frens, ${ }^{45}$ followed by its functionalization with poly(ethylene glycol) (PEG) by adding SDS, a PEGylated chain and $\mathrm{NaOH}$ in order to basify the medium. For $\mathrm{Au} @ \mathrm{COOH}$ synthesis, $52 \mu \mathrm{M}$ of HS-EG(8)- $\left(\mathrm{CH}_{2}\right)_{2}-\mathrm{COOH}(\mathrm{PEG}-\mathrm{COOH})$ were used; for $\mathrm{N}_{3} @ \mathrm{Au} @ \mathrm{COOH} 25: 75$ sat, $13 \mu \mathrm{M}$ of $\mathrm{HS}-\left(\mathrm{CH}_{2}\right)_{3}$ CONH-EG(6)- $\left(\mathrm{CH}_{2}\right)_{2}-\mathrm{N}_{3}\left(\mathrm{PEG}-\mathrm{N}_{3}\right)$ and $39 \mu \mathrm{M}$ of PEG-COOH were used. $^{36}$ In both cases, the mixture was incubated at room temperature for 16 hours, followed by its purification by centrifugation with MiliQ water and the number of PEG chains was quantified by Ellman's method. ${ }^{\mathbf{4 1 , 4 6}}$ The functionalization with G(RGD)S and (2-aminoethyl)trimethylammonium chloride hydrochloride $\left(\mathrm{R}^{\prime} \mathrm{R}_{3} \mathrm{~N}^{+}\right)$was carried out by conjugation with the carboxylic groups on the AuNPs using EDC (1-ethyl-3-(3dimethylaminopropyl)carbodiimide) (Sigma) and sulfo-NHS (sulfo-hydroxysuccinimide) (Sigma) at pH 6 (50 mM MES). Samples were centrifuged 3 times at $14000 \mathrm{rpm}$ for 30 minutes at $4{ }^{\circ} \mathrm{C}$ in order to remove the excess of reactants and final AuNPs were resuspended in distilled $\mathrm{H}_{2} \mathrm{O}$, sterilized by $0.22 \mu \mathrm{m}$ syringe filter and were kept at $4{ }^{\circ} \mathrm{C}$ and protected from light.

Characterization was carried out by UV-Vis spectroscopy analyzing the peak centered at $519 \mathrm{~nm}$ due to the surface plasmon resonance using a Varian Cary50 and FT-IR using a Jasco FT-IR4100 and KBr pills. Morphology and size were evaluated by transmission electron microscopy (TEM) using a FEI TECNAI T20 microscope at $80 \mathrm{kV}$ by placing a drop of the dispersion on a carbon-coated copper grid. The average particle sizes were measured using Image software from the TEM images. More details on the synthesis and confirmation of the amount of RGD and $\mathrm{R}^{\prime} \mathrm{R}_{3} \mathrm{~N}^{+}$attached are detailed in the ESI. $\dagger$

\section{Cell culture}

Mesenchymal stem cells from C57BL/6 strain were used (Gibco, Thermo Fisher Scientific), and grown in MesenCult ${ }^{\mathrm{TM}}$ basal media (StemCell Technologies Inc) containing $10 \%$ of mesenchymal stem cell stimulatory supplements (StemCell Technologies Inc), 100 units per $\mathrm{mL}$ of penicillin and $100 \mathrm{~g} \mathrm{~mL}^{-1}$ of streptomycin at $37{ }^{\circ} \mathrm{C}$ and $5 \% \mathrm{CO}_{2}$ and $3 \% \mathrm{O}_{2}$. Cervical carcinoma cell line HeLa, human embryonic kidney 293, and U251MG glioma cells were obtained from Cancer Research-UK Cell Services. Those cells were cultured in Dulbecco's modified Eagle's medium (DMEM, Lonza) with 10\% heat inactivated fetal bovine serum, $2 \mathrm{mM}$ L-glutamine, 100 units per $\mathrm{mL}$ penicillin, $100 \mu \mathrm{g} \mathrm{mL}{ }^{-1}$ streptomycin and $250 \mu \mathrm{g} \mathrm{mL}^{-1}$ amphotericin $\mathrm{B}$ (Lonza) and maintained at $37{ }^{\circ} \mathrm{C}$ in $5 \% \mathrm{CO}_{2}$ and $\mathrm{O}_{2}$ to saturation.

\section{Adenoviral vectors}

Replication-incompetent Adenovirus Type 5 Ad-CMV-GFP (E1/ E3) was obtained from Vector Biolabs.

\section{Cellular viability}

Cells were seeded at a density of $2 \times 10^{4}$ cells per well in 96-well plates and cellular viability was evaluated by the MTT assay (Invitrogen) following the standard protocol provided by the supplier.

\section{Formation of complexes and infection}

For a first screening, cells were seeded at a density of $1 \times 10^{4}$ cells per well in 96-well plates and grown for $24 \mathrm{~h}$ prior to 
infection. Ad at 25-1000 MOI and 0.01-0.1 pmol AuNPs were used. For the formation of the complexes, Ad was mixed with the AuNPs in cell culture medium without serum for 20 minutes at room temperature. $250 \mu \mathrm{L}$ were added to the cells and incubated for 45 minutes at $37^{\circ} \mathrm{C}$. After that, complete medium with serum was added to the wells and they were incubated at $37{ }^{\circ} \mathrm{C}$ for 48 hours. Every experiment was carried out in triplicate. For next experiments, cells were seeded at a density of $2 \times 10^{4}$ cells per well in 24-well plates and 25 MOI and 0.04 pmol of AuNPs were used. Ad and Ad with JetPEI-RGD ${ }^{\mathrm{TM}}$ (Polyplus Transfection) were used as positive controls. $5 \times 10^{5}$ pfu of Ad5-CMVGFP were diluted in $100 \mu \mathrm{L}$ of $\mathrm{NaCl} 150 \mathrm{mM}$, mixed with $3.1 \mu \mathrm{L}$ of JetPEI-RGD in $100 \mu \mathrm{L}$ of $\mathrm{NaCl} 150 \mathrm{mM}$ and vortexed. The mixture was incubated at room temperature for 15-30 minutes prior to adding it to the cells.

To evaluate GFP expression, cells were centrifuged three times, resuspended in PBS and $10^{4}$ events analyzed by flow cytometry using a FACSAria cytometer (BD Biosciences) and CellQuest Pro software (BD Biosciences).

For the analysis by fluorescence microscopy, cells were seeded on coverslips and after 48 hours of infection, they were fixed with glutaraldehyde $4 \%$ in PBS at room temperature for 10 minutes. Nuclei were stained with DAPI and microtubules with streptavidin-Texas Red using as primary antibody mouse anti- $\beta$ tubulin (ESI $\dagger$ ). For every sample, images were taken for GFP $(499 / 520 \mathrm{~nm})$, for Texas (558/575 nm) and for DAPI (359/461 nm) in a Nikon Eclipse Ti inverted microscope and images were analyzed using ImageJ.

\section{Scanning electron microscopy analysis (SEM)}

Following infection of MSCs with Ad@AuNPs and after $48 \mathrm{~h}$ of incubation, $1 \mathrm{~mL}$ of glutaraldehyde $4 \%$ in cacodylate buffer $0.2 \mathrm{M}$ (pH 7.2) was added and the sample was kept at $4{ }^{\circ} \mathrm{C}$ for 2 hours. Next, the content of each well was replaced with $1 \mathrm{~mL}$ of glutaraldehyde $2 \%$ in cacodylate buffer $0.1 \mathrm{M}(\mathrm{pH} 7.2)$ and left overnight at $4{ }^{\circ} \mathrm{C}$. Then samples were washed twice with the cacodylate buffer $0.1 \mathrm{M}$ and dehydrated with aqueous solutions of $\mathrm{MeOH} 30 \%$, $\mathrm{MeOH} 50 \%$ and $\mathrm{MeOH} 70 \%$ at room temperature twice for 5 minutes. Finally, $\mathrm{MeOH} 100 \%$ was added twice for 10 minutes and $\mathrm{MeOH} 100 \%$ anhydride twice for 5 minutes. Samples were kept in that medium at $4{ }^{\circ} \mathrm{C}$ until covered with gold and mounted on SEM sample holders.

\section{Results and discussion}

\section{Synthesis and characterization of gold nanoparticles}

AuNPs of an average diameter of $14 \mathrm{~nm}$ were chosen because of their high monodispersity and suitable size for efficient transfection without inducing high toxic effects as smaller nanomaterials. ${ }^{47}$ The selected AuNPs were functionalized as depicted in Fig. 1. First, gold nanoparticles were synthesized by reduction of a gold salt with sodium citrate and subsequently stabilized by saturation of the surface with polyethyleneglycol (PEG) (Fig. S1†). PEG modification of nanoparticles affords a longcirculating system and passive targeting to tumors by decreasing the non-specific adsorption of proteins because of

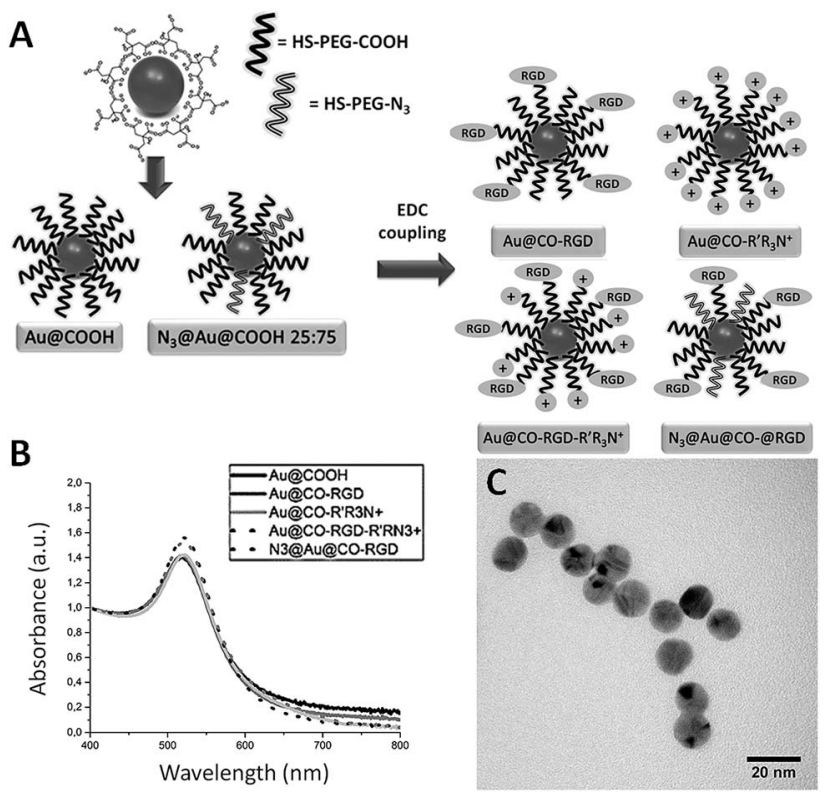

Fig. 1 Functionalization and characterization of AuNPs. (A) Scheme of the stabilization of gold nanoparticles synthesized by reduction with sodium citrate with either one or two different pegylated chains and further functionalization by EDC coupling reaction with (2-aminoethyl) trimethylammonium hydrochloride $\left(\mathrm{R}^{\prime} \mathrm{R}_{3} \mathrm{~N}^{+}\right)$and/or RGD. Characterization of the AuNPs by (B) UV-Vis spectroscopy and (C) TEM.

its amphiphilic nature and therefore slows down the macrophage-mediated uptake and removal from the systemic circulation. ${ }^{48-50}$ Besides, it is known to increase biocompatibility $^{51,52}$ and provides the most adequate chemical groups for a covalent binding with several biomolecules and flexibility to that attached ligands for efficient interaction with their target. ${ }^{53}$ Two different thiolated chains were used for the stabilization: a carboxylated PEG (HS-PEG(8)-COOH) (Au@COOH); or a PEG with an azide group (HS-PEG(8)- $\mathrm{N}_{3}$ ), alternating with carboxylic PEG chains $\left(\mathrm{N}_{3} @ A u @ C O O H \quad 5: 75\right)$, taking advantage of the fact that this functional group is a zwitterion so it reduces the initial negative charge of the nanoparticle. Also, the strong bond established between gold and sulphur atoms, considered covalent or quasi covalent by some authors, is the most frequently used for a quick and easy conjugation with AuNPs. ${ }^{54,55}$ AuNPs were further functionalized with a (i) positively charged molecule (2-aminoethyl)trimethylammonium hydrochloride $\left(\mathrm{R}^{\prime} \mathrm{R}_{3} \mathrm{~N}^{+}\right)$, to promote the electrostatic interaction with the proteoglycans; and/or (ii) the motive arginine-glycineaspartic acid (RGD), to promote binding to integrins $\alpha v \beta 3$ and $\alpha v \beta 5$, improving internalization by endocytosis. The functionalization with $\mathrm{R}^{\prime} \mathrm{R}_{3} \mathrm{~N}^{+}$and RGD was achieved by formation of amide bonds between carboxylic and amine groups through EDC coupling reaction. ${ }^{56}$ Thus, four types of AuNPs were designed to promote either the positive interaction with the membrane of the MSCs, the attachment to integrins, or both: $\mathrm{Au} @ \mathrm{CO}-\mathrm{R}^{\prime} \mathrm{R}_{3} \mathrm{~N}^{+}, \quad \mathrm{Au} @ \mathrm{CO}-\mathrm{RGD}-\mathrm{R}^{\prime} \mathrm{R}_{3} \mathrm{~N}^{+}, \quad \mathrm{Au}$ @CO-RGD, $\mathrm{N}_{3} @ A u @ C O-R G D$. UV-Vis spectroscopy (Fig. 1B) and TEM images (Fig. 1C) demonstrated the formation of monodisperse spherical AuNPs of $14 \mathrm{~nm} \pm 1 \mathrm{~nm}$ in the presence of the 
different coatings. Quantification of the number of PEG chains attached, presence of a positive $\zeta$ potential above $+20 \mathrm{mV}$ in the case of $\mathrm{Au} @ \mathrm{CO}-\mathrm{R}^{\prime} \mathrm{R}_{3} \mathrm{~N}^{+}$and $\mathrm{Au}$ @CO-RGD- $\mathrm{R}^{\prime} \mathrm{R}_{3} \mathrm{~N}^{+}$and functionalization with RGD were also checked (ESI $\dagger$ ).

\section{Cytotoxicity of gold nanoparticles}

An important requirement for a good carrier is low cytotoxicity, even more when it is used in combination with an Ad vector. As can be seen in Fig. 2, all four types of AuNPs were found to be nontoxic at doses ranging from $1 \mathrm{nM}$ to $6 \mathrm{nM}$ between 24 and $72 \mathrm{~h}$. A general trend is observed with decreasing viability in a concentration-dependent manner, with cell viability values above $70 \%$ in all cases. While $\mathrm{N}_{3} @ A u @ C O-R G D$ maintained higher viability values at $72 \mathrm{~h}$, followed by Au@CO-RGD-R ${ }^{\prime} \mathrm{R}_{3} \mathrm{~N}^{+}$ and $\mathrm{Au} @ \mathrm{CO}-\mathrm{RGD}$, with $\mathrm{Au} @ \mathrm{CO}-\mathrm{R}^{\prime} \mathrm{R}_{3} \mathrm{~N}^{+}$the lowest values were obtained, between $70-90 \%$ of cell viability.

\section{Optimization of adenoviral infection with commercial transfection agents}

Although several reports have described the successful transduction of MSCs by various viral and non-viral vector systems, including retrovirus, lentivirus, adeno-associated virus, baculovirus and adenovirus derived vectors, ${ }^{57}$ stem cells exhibit resistance to classical viral vectors, as many primary cells do.

The first objective of our study was to seek a proper commercial transfection reagent for coating Ad vectors that could be used as positive control for MSCs infection by coating enhancement. To this aim, we decided to use JetPEI and JetPEIRGD, a modified complex of polyethyleneimine (PEI) combining the proton sponge effect of PEI and the potential of the RGD motif to increase the internalization via integrins. The net anionic surface charge of Ads, based on the predominance of negatively charge hexon residues, allows them to form complexes by electrostatic attraction and also hydrophobic interactions with both charged and uncharged molecules and particles, including
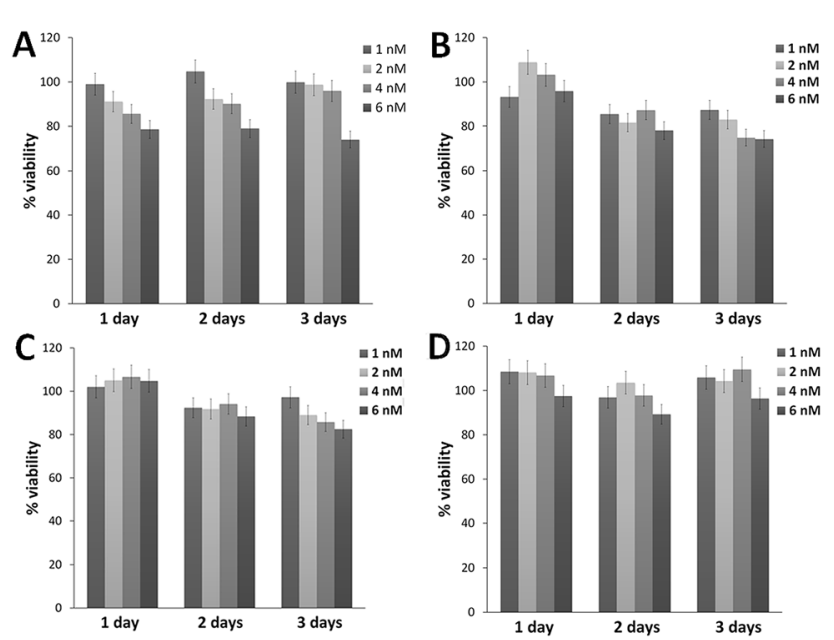

Fig. 2 Evaluation of cell viability by MTT assay after 24-72 h incubation with MSCs, as percentage of control cells without nanoparticles. (A) Au@CO-RGD, (B) Au@CO- $\mathrm{R}^{\prime} \mathrm{R}_{3} \mathrm{~N}^{+}$, (C) Au@CO-RGD- $\mathrm{R}^{\prime} \mathrm{R}_{3} \mathrm{~N}^{+}$and (D) $\mathrm{N}_{3}$ (AuaCO-RGD. cationic liposomes and polymers or polycation-coated metal nanoparticles complexes. ${ }^{58-61}$ Binding of PEI produces the conversion of the negatively charged adenoviruses into positively charged particles capable of interacting with anionic proteoglycans and integrins at the cell surface, helping the viruses to enter the cells by endocytosis. In general, this type of chemical modification is easily accomplished by incubating the virus with the cationic component, which leads to electrostatically-induced aggregation. ${ }^{62}$ Combining polycations and cationic lipids complexes with adenovirus has already shown to enhance transduction of target cells, facilitating in vitro transduction of MSCs. ${ }^{63}$ However, these methodologies remain below the levels of transduction that can be achieved with Ad/PEI-RGD, as they reached the maximum expression levels at doses 3 folds higher than using just the cationic forms. Surprisingly, the use of an RGD-conjugated PEI has also been shown to transduce MSCs with pDNA, but the efficiency of transfection was lower than that obtained with adenovirus alone. ${ }^{64}$

The enhancement on expression when we compared viral infection at 250 and 400 MOI using a non-replicative Ad expressing GFP alone (Ad-GFP), a liposomal formulation (Lipofectamine) and a branched PEI derivate (JetPEI) with and without functionalization with the RGD peptide coating the AdGFP, was noticeable (Fig. 3). Complexion of the adenovirus with Lipofectamine led to an increase (26\%) in the number of GFPpositive cells. Previous studies used 3000 MOI to reach optimal results, ${ }^{65}$ but we achieved higher infection efficiency using 10-15 times less viral particles. Gene transfer and expression was further enhanced (73\%) when JetPEI was used (Ad-Jet/PEI). As expected, expression of the GFP reporter was even higher when the RGD peptide was present on the surface of the transduction complex (Ad-Jet/PEI-RGD), reaching nearly a $100 \%$ transduction efficiency. The level of GFP protein expression remained constant at higher MOI when using the Ad alone or in combination with Lipofectamine or JetPEI-RGD, while there was a moderate increase when JetPEI was used as coating (Fig. 3C and $\mathrm{S} 5 \dagger$ ). Our results are consistent with previous observations suggesting that bone marrow MSCs have

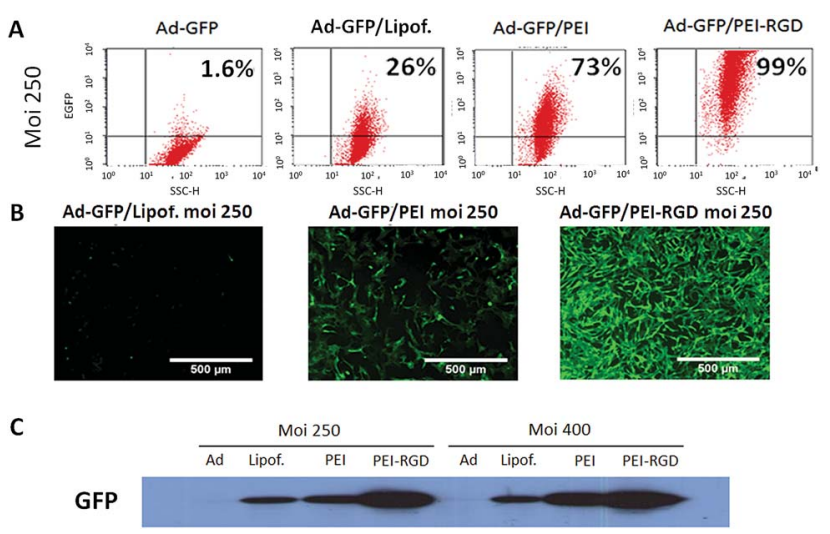

Fig. 3 Comparison on the transduction efficiency of Ad vectors coated with Lipofectamine (Lipof), PEI and PEI-RGD on MSCs at $48 \mathrm{~h}$, in terms of GFP expression analyzed by flow cytometry (A), fluorescence microscopy (scale bar $=500 \mu \mathrm{m}$ ) (B) and western-blot (C). 
a low CAR expression (Fig. S4B $\dagger$ ), which significantly affects Ad efficiency. ${ }^{66}$ Despite the good results obtained with Ad-JetPEIRGD, the MOI used to achieve those results was 5 times higher compared to standard doses for CAR-positive cells (5-50 MOI), making more complicated the scalability into the clinic. More importantly, the surface marker profile of MSC cells was analysed before and after infection (Table S1 $\dagger$ ), and no significant changes were found on Sca-1 and CD73 (positive) or CD45 and CD31 (negative) (ESI $\dagger$ ).

\section{Adenoviral efficiency using gold nanoparticles as coating}

Based on the chemical modification of Ad, we synthesized $14 \mathrm{~nm}$ AuNPs stabilized using bifunctional poly(ethylene glycol) (PEG) with a terminal thiol group at one end and a carboxyl or an azide group on the other. ${ }^{67}$ AuNPs were further functionalized to explore the effect on the infection levels by changing the net charge of the system via introduction of a zwitterion specie (azide groups, $\mathrm{N}_{3}$ ) or quaternary ammonium groups (to enhance the approach to the cell membrane via ionic interaction with glucosaminoglycans) and with the introduction of RGD motifs (for the attachment to the $\alpha v \beta 3$ and $\alpha v \beta 5$ integrins). For a first screening for the optimal conditions, MSCs were seeded in 96 well-plates and infected varying both the concentration of Ads and nanoparticles. AuNPs were complexed with adenovirus (Ad@AuNP) in medium without fetal bovine serum (FBS) for 20 minutes and subsequently incubated with cells for 45 minutes before adding supplement media. As controls the adenovirus alone and the virus coated with JetPEI-RGD as previously optimized were used. To evaluate the transduction efficiency by fluorescence microscopy, first the amount of virus was varied from 25 to 125 MOI while keeping the AuNPs concentration fixed at 0.1 pmol (Fig. 4 first row). Since the best results were obtained using Au@CO- $\mathrm{R}^{\prime} \mathrm{R}_{3} \mathrm{~N}^{+}$at $50 \mathrm{MOI}$, this Ad concentration was selected and the amount of AuNPs used reduced to 0.01 and 0.05 pmol (Fig. 4 lower row). These results indicated that the excess of AuNPs had an enhancing effect on infection

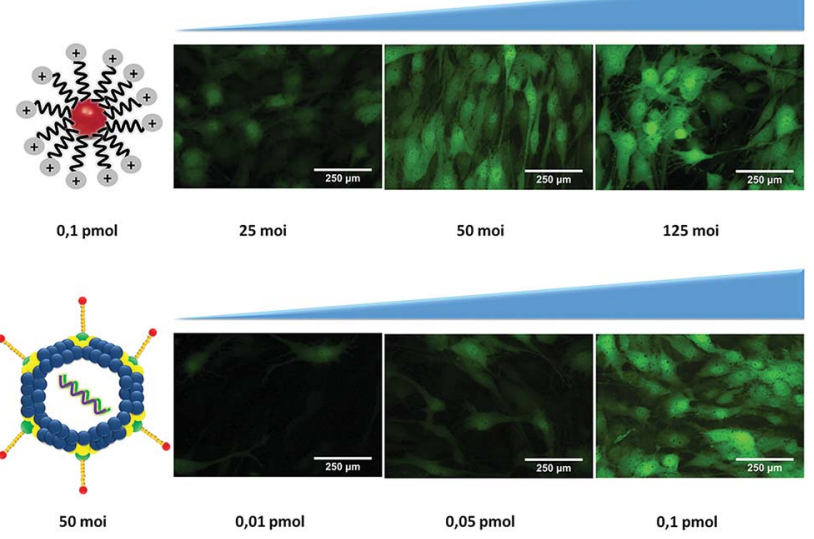

Fig. 4 Optimization of AdaAuNPs complex concentration. Analysis of GFP expression by fluorescence microscopy after $48 \mathrm{~h}$ of infection of MSCs, first maintaining the concentration of Au@CO- $\mathrm{R}^{\prime} \mathrm{R}_{3} \mathrm{~N}^{+}$at 0.1 pmol per well (upper row) and after maintaining the concentration of Ad at $50 \mathrm{MOI}$ (lower row). and that using $0.1 \mathrm{pmol}$ of AuNPs induced an optimal infection and good values of GFP expression, making it possible to reduce the amount of adenovirus as low as $25 \mathrm{MOI}$, and still obtain acceptable transduction levels.

Next, we scaled up the experiments and doubled the concentration of AuNPs ( $0.4 \mathrm{pmol} / 25 \mathrm{MOI})$, in order to analyze in more detail the effect of each type of AuNPs used at the lowest concentration of adenovirus previously tested. In Fig. 5, results show that transduction levels in control samples were low using only Ad (around 13\% of GFP-positive cells) and increased up to $27 \%$ when the Ad was complexed with JetPEI-RGD, still far from being an efficient infection (Fig. 5Ai and ii). Similar values were obtained using Ad@ $\mathrm{N}_{3}$ @Au@CO-RGD complexes (Fig. 5Avi), with a two-fold increase with Ad@Au@CO-RGD complexes (41\%) (Fig. 5Aiii and S6 $\dagger$ ), probably based on the increased functionalization with RGD groups thanks to the amount of carboxylic groups of PEG present on the surface of Au@CORGD; this would improve recognition by integrins on the cell membrane. However, the best results were obtained with the complexes formed with AuNPs bearing positive charges on their surface; that is, Ad@Au@CO- $\mathrm{R}^{\prime} \mathrm{R}_{3} \mathrm{~N}^{+}$and Ad@Au@CO-RGD$\mathrm{R}^{\prime} \mathrm{R}_{3} \mathrm{~N}^{+}$, which produced a three-fold increase on infection efficiency (90\% and 86\% GFP-positive cells, respectively) compared to the results obtained with the commercial reagent (Fig. 5Aiv and v). Samples were analyzed by scanning electron microscopy
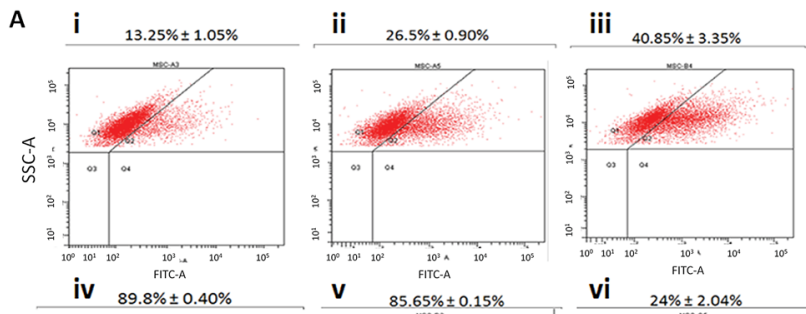
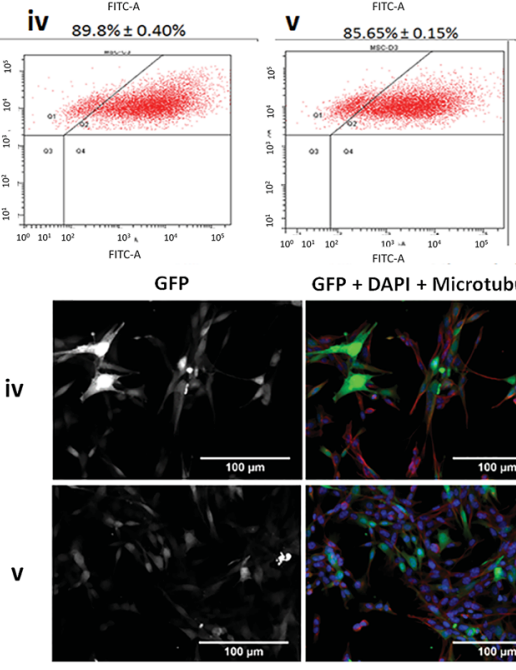

GFP + DAPI + Microtubules

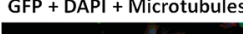

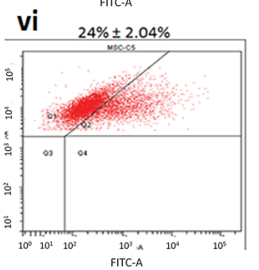
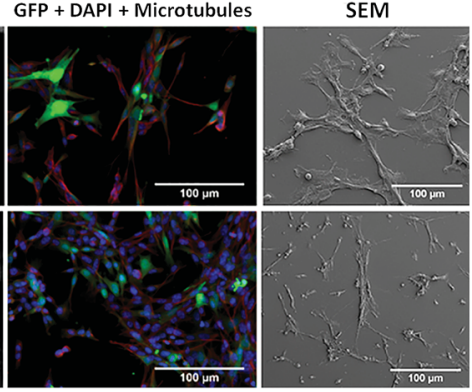

Fig. 5 Transduction efficiency of Ad vectors coated with the four types of modified gold nanoparticles on MSCs at $48 \mathrm{~h}$, in terms of GFP expression analyzed by flow cytometry (A) and fluorescence microscopy (B) (scale bar $=100 \mu \mathrm{m}$ ). Ad at $25 \mathrm{MOI}$ and $0.4 \mathrm{pmol}$ AuNPs were used. (i) Ad; (ii) AdaJetPEl-RGD; (iii) Ad@Au@CO-RGD, (iv) AdaAuaCO- $\mathrm{R}^{\prime} \mathrm{R}_{3} \mathrm{~N}^{+}$; (v) AdaAuaCO-RGD- $\mathrm{R}^{\prime} \mathrm{R}_{3} \mathrm{~N}^{+}$; and (vi) AdaAuaN $3-C O-R G D$. Nuclei were stained with DAPI (blue), microtubules with Texas Red (red) and GFP is seen in grey. SEM images are shown in the right column. 


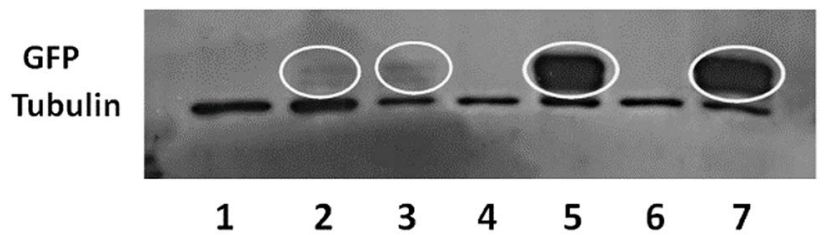

\begin{tabular}{|c|c|c|}
\hline Well & Adenovirus & Infection agent \\
\hline 1 & - & - \\
2 & + & - \\
3 & + & Jet-PEI-RGD \\
4 & - & $A u @ C O-R^{\prime} R_{3} N^{+}$ \\
5 & + & $A u @ C O-R^{\prime} R_{3} N^{+}$ \\
6 & - & $A u @ C O-R^{\prime} R_{3} N^{+} y R G D$ \\
7 & + & $A u @ C O-R^{\prime} R_{3} N^{+} y R G D$ \\
\hline
\end{tabular}

Fig. 6 Analysis of the expression of GFP depending on the system used for the infection, using tubulin as control.

(SEM) in order to assess the effects of the AuNPs on MSCs, observing an intact morphology (Fig. 5B).

Contrary to what happened when comparing the efficiency of coating with JetPEI with or without RGD, in the case of AuNPs functionalized with the quaternary ammonium there was no significant difference on the presence or absence of RGD. This may be due to the fact that in commercial JetPEI the positive charge is provided by primary and secondary amines. However, quaternary ammonium groups contribute with a high and positive charge that remains constant along the whole range of $\mathrm{pH}$, masking the effect of RGD. This difference in the source of the positive charge between the JetPEI-RGD and our AuNPs also explains the increase on infection rates found when using a lower MOI. Analysis of GFP expression by fluorescence microscopy (Fig. 5B) and western-blot (Fig. 6) confirmed the highly effective infection of these systems when introducing quaternary ammonium groups.

Thus, an effective ionic interaction proved to be more critical than the presence of RGD motifs exposed on the surface. This result can be explained on the base of quick and non-specific ionic interactions, increasing the number of viral particles in closer contact to the cell membrane. On the other hand, RGD implies a slower and more specific recognition process, lowering the possibility of proceeding with an effective infection.

Finally, when compared to the transduction efficiency on a CAR-positive cell line as U-251MG using Ad alone (traditional system), we observed values lower than those obtained when using our system in MSCs (Fig. S7 $\dagger$ ), suggesting that AuNPs coating induces higher infection levels than the natural pathways of infection of Ad. In summary, we could say that our strategy increased the infection efficiency of Ad on a cell line with low CAR receptor expression.

\section{Conclusions}

We have described a new approach for increased infection efficiency of low Ad concentrations on MSCs, a refractory cell line lacking CAR expression. This design is based on the use of positively-charged pegylated AuNPs further functionalized to bear positive charge and/or the RGD peptide to coat Ad. This study shows an easy and effective way for the genetic modification of MSCs with lower risk and no cytotoxic effects, broadening their application in cell therapy.

\section{Conflicts of interest}

There are no conflicts to declare.

\section{Acknowledgements}

This work was supported by Araid Fund; by the Government of Aragon through a PhD grant (B054/12); Fundación Mutua Madrileña Automovilística (MMA); Instituto de Salud Carlos III, and ERANET-NANOSCIERA NANOTRUCK projects. Special thanks to Valeria Grazu, Rodrigo Dieguez and Victoria MoleiroSan Emeteiro for their involvement and advice on the project. The authors thank the Cell Culture, Microscopy, Cytometry and Pathology from IACS and INA Scientific Services for their help and access to their instruments.

\section{References}

1 R. Dwyer and M. Kerin, Hum. Gene Ther., 2010, 21, 15061512.

2 Y. Iwasaki, M. Ueda, T. Yamada, A. Kondo, M. Seno, K. Tanizawa, S. Kuroda, M. Sakamoto and M. Kitajima, Cancer Gene Ther., 2007, 14, 74.

3 G. Prud'Homme, R. Draghia-Akli and Q. Wang, Gene Ther., 2007, 14, 553.

4 J. Ruan, J. Shen, Z. Wang, J. Ji, H. Song, K. Wang, B. Liu, J. Li and D. Cui, Int. J. Nanomed., 2011, 6, 425.

5 Y. Wang, N. Z. Mostafa, C. Y. Hsu, L. Rose, C. Kucharki, J. Yan, H. Jiang and H. Uludağ, J. Surg. Res., 2013, 183, 8-17.

6 T. Niidome and L. Huang, Gene Ther., 2002, 9, 1647.

7 P. Mancheño-Corvo and P. Martín-Duque, Clin. Transl. Oncol., 2006, 8, 858-867.

8 I. Kovesdi, D. E. Brough, J. T. Bruder and T. J. Wickham, Curr. Opin. Biotechnol., 1997, 8, 583-589.

9 S. C. Hung, C. Y. Lu, S. K. Shyue, H. C. Liu and L. L. T. Ho, Stem Cells, 2004, 22, 1321-1329.

10 H. Mizuguchi and T. Hayakawa, Hum. Gene Ther., 2004, 15, 1034-1044.

11 G. Jiang, Y. Xin, J. N. Zheng and Y. Q. Liu, Int. J. Cancer, 2011, 129, 263-274.

12 J. Grove and M. Marsh, J. Cell Biol., 2011, 195, 1071-1082.

13 M. Dechecchi, P. Melotti, A. Bonizzato, M. Santacatterina, M. Chilosi and G. Cabrini, J. Virol., 2001, 75, 8772-8780.

14 N. B. Nardi and L. da Silva Meirelles, in Stem cells, Springer, 2008, pp. 249-282.

15 M. Dominici, K. Le Blanc, I. Mueller, I. Slaper-Cortenbach, F. Marini, D. Krause, R. Deans, A. Keating, D. Prockop and E. Horwitz, Cytotherapy, 2006, 8, 315-317.

16 C. Schug, W. Sievert, S. Urnauer, A. M. Müller, K. A. Schmohl, A. Wechselberger, N. Schwenk, K. Lauber, M. Schwaiger, 
G. Multhoff, E. Wagner, P. J. Nelson and C. Spitzweg, Hum. Gene Ther., 2018, 29, 1287-1300.

17 C. Belmar-Lopez, G. Mendoza, D. Oberg, J. Burnet, C. Simon, I. Cervello, M. Iglesias, J. C. Ramirez, P. Lopez-Larrubia and M. Quintanilla, BMC Med., 2013, 11, 139.

18 L. Pereboeva, S. Komarova, G. Mikheeva, V. Krasnykh and D. Curiel, Stem Cells, 2003, 21, 389-404.

19 N. D'souza, J. S. Burns, G. Grisendi, O. Candini, E. Veronesi, S. Piccinno, E. M. Horwitz, P. Paolucci, P. Conte and M. Dominici, in Mesenchymal Stem Cells-Basics and Clinical Application II, Springer, 2012, pp. 209-266.

20 A. Nakamizo, F. Marini, T. Amano, A. Khan, M. Studeny, J. Gumin, J. Chen, S. Hentschel, G. Vecil and J. Dembinski, Cancer Res., 2005, 65, 3307-3318.

21 M. Studeny, F. C. Marini, J. L. Dembinski, C. Zompetta, M. Cabreira-Hansen, B. N. Bekele, R. E. Champlin and M. Andreeff, J. Natl. Cancer Inst., 2004, 96, 1593-1603.

22 C. Latorre-Romero, M. R. Marin-Yaseli, C. Belmar-Lopez, R. del Moral, P. C. Marijuan, M. Quintanilla and P. MartinDuque, Clin. Transl. Oncol., 2011, 13, 10-17.

23 Y.-L. Si, Y.-L. Zhao, H.-J. Hao, X.-B. Fu and W.-D. Han, Ageing Res. Rev., 2011, 10, 93-103.

24 C. S. Lee, E. S. Bishop, R. Zhang, X. Yu, E. M. Farina, S. Yan, C. Zhao, Z. Zeng, Y. Shu and X. Wu, Genes Dis., 2017, 4, 4363.

25 J. M. Bergelson, Biochem. Pharmacol., 1999, 57, 975-979.

26 C. Hagedorn and F. Kreppel, Hum. Gene Ther., 2017, 28, 820832.

27 H. Mizuguchi, T. Sasaki, K. Kawabata, F. Sakurai and T. Hayakawa, Biochem. Biophys. Res. Commun., 2005, 332, 1101-1106.

28 J. Han, D. Zhao, Z. Zhong, Z. Zhang, T. Gong and X. Sun, Nanotechnology, 2010, 21, 105106.

29 P.-H. Kim, T.-i. Kim, J. W. Yockman, S. W. Kim and C.-O. Yun, Biomaterials, 2010, 31, 1865-1874.

30 S.-Y. Kim, S.-J. Lee, J.-K. Kim, H.-G. Choi and S.-J. Lim, Int. J. Nanomed., 2017, 12, 7323.

31 J. Conde, F. Tian, Y. Hernández, C. Bao, D. Cui, K.-P. Janssen, M. R. Ibarra, P. V. Baptista, T. Stoeger and M. Jesús, Biomaterials, 2013, 34, 7744-7753.

32 M. De, P. S. Ghosh and V. M. Rotello, Adv. Mater., 2008, 20, 4225-4241.

33 P. Ghosh, G. Han, M. De, C. K. Kim and V. M. Rotello, Adv. Drug Delivery Rev., 2008, 60, 1307-1315.

34 D. A. Giljohann, D. S. Seferos, W. L. Daniel, M. D. Massich, P. C. Patel and C. A. Mirkin, Angew. Chem., Int. Ed., 2010, 49, 3280-3294.

35 E. Polo, P. del Pino, B. Pelaz, V. Grazu and M. Jesus, Chem. Commun., 2013, 49, 3676-3678.

36 M. M. Encabo-Berzosa, M. Gimeno, L. Lujan, M. SanchoAlbero, L. Gomez, V. Sebastian, M. Quintanilla, M. Arruebo, J. Santamaria and P. Martin-Duque, RSC Adv., 2016, 6, 58723-58732.

37 G. Cifter, J. Chin, F. Cifter, Y. Altundal, N. Sinha, E. Sajo and W. Ngwa, Phys. Med., 2015, 31, 1070-1074.

38 J. Schuemann, Y. Lin, H. Paganetti and S. McMahon, Int. J. Radiat. Oncol., Biol., Phys., 2015, 93, S43.
39 M. M. Encabo-Berzosa, M. Sancho-Albero, V. Sebastian, S. Irusta, M. Arruebo, J. Santamaria and P. Martín Duque, J. Gene Med., 2017, 19, e2964.

40 D. Pissuwan, T. Niidome and M. B. Cortie, J. Controlled Release, 2011, 149, 65-71.

41 J. Conde, A. Ambrosone, V. Sanz, Y. Hernandez, V. Marchesano, F. Tian, H. Child, C. C. Berry, M. R. Ibarra and P. V. Baptista, ACS Nano, 2012, 6, 8316-8324.

42 J. E. Gagner, M. D. Lopez, J. S. Dordick and R. W. Siegel, Biomaterials, 2011, 32, 7241-7252.

43 L. A. Gearheart, H. J. Ploehn and C. J. Murphy, J. Phys. Chem. $B, 2001,105,12609-12615$.

44 J. Turkevich, P. C. Stevenson and J. Hillier, Discuss. Faraday Soc., 1951, 11, 55-75.

45 G. Frens, Nature Physical Science, 1973, 241, 20.

46 V. Marchesano, Y. Hernandez, W. Salvenmoser, A. Ambrosone, A. Tino, B. Hobmayer, J. M. de la Fuente and C. Tortiglione, ACS Nano, 2013, 7, 2431-2442.

47 Y. Pan, S. Neuss, A. Leifert, M. Fischler, F. Wen, U. Simon, G. Schmid, W. Brandau and W. Jahnen-Dechent, Small, 2007, 3, 1941-1949.

48 E. J. Chisholm, G. Vassaux, P. Martin-Duque, R. Chevre, O. Lambert, B. Pitard, A. Merron, M. Weeks, J. Burnet and I. Peerlinck, Cancer Res., 2009, 69, 2655-2662.

49 P. C. Chen, S. C. Mwakwari and A. K. Oyelere, Nanotechnol., Sci. Appl., 2008, 1, 45.

50 G. F. Paciotti, L. Myer, D. Weinreich, D. Goia, N. Pavel, R. E. McLaughlin and L. Tamarkin, Drug Delivery, 2004, 11, 169-183.

51 W. Eck, G. Craig, A. Sigdel, G. Ritter, L. J. Old, L. Tang, M. F. Brennan, P. J. Allen and M. D. Mason, ACS Nano, 2008, 2, 2263-2272.

52 S.-D. Li and L. Huang, Mol. Pharmaceutics, 2008, 5, 496-504.

53 J. Chen, P. Gao, S. Yuan, R. Li, A. Ni, L. Chu, L. Ding, Y. Sun, X.-Y. Liu and Y. Duan, ACS Nano, 2016, 10, 11548-11560.

54 C. D. Bain, J. Evall and G. M. Whitesides, J. Am. Chem. Soc., 1989, 111, 7155-7164.

55 R. A. Sperling and W. J. Parak, Philos. Trans. R. Soc., A, 2010, 368, 1333-1383.

56 J. V. Staros, R. W. Wright and D. M. Swingle, Anal. Biochem., 1986, 156, 220-222.

57 K. Ozawa, K. Sato, I. Oh, K. Ozaki, R. Uchibori, Y. Obara, Y. Kikuchi, T. Ito, T. Okada and M. Urabe, J. Autoimmun., 2008, 30, 121-127.

58 R. Alemany, K. Suzuki and D. T. Curiel, J. Gen. Virol., 2000, 81, 2605-2609.

59 H. Gosnell, L. M. Kasman, T. Potta, L. Vu, E. Garrett-Mayer, K. Rege and C. Voelkel-Johnson, J. Controlled Release, 2014, 176, 35-43.

60 N. Mendez, V. Herrera, L. Zhang, F. Hedjran, R. Feuer, S. L. Blair, W. C. Trogler, T. R. Reid and A. C. Kummel, Biomaterials, 2014, 35, 9554-9561.

61 R. Singh and K. Kostarelos, Trends Biotechnol., 2009, 27, 220229.

62 P. A. Conget and J. J. Minguell, Exp. Hematol., 2000, 28, 382390. 
63 K. Kawabata, F. Sakurai, N. Koizumi, T. Hayakawa and H. Mizuguchi, Mol. Pharmaceutics, 2006, 3, 95-103.

64 B. A. Clements, J. Bai, C. Kucharski, L.-L. Farrell, A. Lavasanifar, B. Ritchie, A. Ghahary and H. Uludağ, Biomacromolecules, 2006, 7, 1481-1488.

65 M. Studeny, F. C. Marini, R. E. Champlin, C. Zompetta, I. J. Fidler and M. Andreeff, Cancer Res., 2002, 62, 3603-3608.
66 T. Suzuki, K. Kawamura, Q. Li, S. Okamoto, Y. Tada, K. Tatsumi, H. Shimada, K. Hiroshima, N. Yamaguchi and M. Tagawa, BMC Cancer, 2014, 14, 713.

67 D. Shenoy, W. Fu, J. Li, C. Crasto, G. Jones, C. DiMarzio, S. Sridhar and M. Amiji, Int. J. Nanomed., 2006, 1, 51. 